\title{
The relation between children's constructive play activities, spatial ability, and mathematical word problem-solving performance: a mediation analysis in sixth-grade students
}

\section{Meike Oostermeijer, Anton J. H. Boonen* and Jelle Jolles}

Faculty of Psychology and Education, Department of Educational Neuroscience, VU University, Amsterdam, Netherlands

\section{Edited by: \\ Layne Kalbfleisch, George Mason \\ University, USA}

Reviewed by:

Li-Jen Kuo, Northern Illinois

University, USA

Jason Steffener, Columbia University, USA

\section{*Correspondence:}

Anton J. H. Boonen, Faculty of Psychology and Education,

Department of Educational Neuroscience, VU University, Van der Boechorststraat 1, 1081 BT Amsterdam, Netherlands e-mail: a.j.h.boonen@vu.nl
The scientific literature shows that constructive play activities are positively related to children's spatial ability. Likewise, a close positive relation is found between spatial ability and mathematical word problem-solving performances. The relation between children's constructive play and their performance on mathematical word problems is, however, not reported yet. The aim of the present study was to investigate whether spatial ability acted as a mediator in the relation between constructive play and mathematical word problemsolving performance in 128 sixth-grade elementary school children. This mediating role of spatial ability was tested by utilizing the current mediation approaches suggested by Preacher and Hayes (2008). Results showed that $38.16 \%$ of the variance in mathematical word problem-solving performance is explained by children's constructive play activities and spatial ability. More specifically, spatial ability acted as a partial mediator, explaining $31.58 \%$ of the relation between constructive play and mathematical word problem-solving performance.

\section{Keywords: constructive play, spatial ability, mental rotation, mathematical word problem-solving performance,} elementary school

\section{INTRODUCTION}

In its home and school environment, almost every child is involved in playing with Legos, blocks, and jigsaw puzzles. The term constructive play, which has a central role in this study, is often used to categorize these play activities. Constructive play generally involves the manipulation, construction, and motion of objects in space (i.e., rotating, Mitchell, 1973; Pomerleau et al., 1990; Caldera et al., 1999). The aim of the present study is to examine the link between children's constructive play activities and two interrelated factors, namely spatial ability and mathematical word problem-solving performance. Although a positive relation between constructive play and spatial ability is reported by several authors (e.g., Bjorklund and Douglas-Brown, 2008; Levine et al., 2012) as well as a positive relation between spatial ability and mathematical word problem-solving performance (Blatto-Vallee et al., 2007; Beentjes, 2008; Casey et al., 2008), a relation between constructive play and mathematical word problem-solving performance is barely investigated. A possible reason for this absence is that spatial ability acts as a mediator in the relation between children's constructive play activities and their performances on mathematical word problems. The present study is primarily focused on testing this mediating role of spatial ability.

\section{THE RELATION BETWEEN CONSTRUCTIVE PLAY AND SPATIAL ABILITY}

The majority of the studies that examined constructive play has focused on its relation with (the development of) spatial ability (e.g., Grimshaw et al., 2002; Bjorklund and Douglas-Brown, 2008; Levine etal., 2012). Spatial ability involves the ability to represent, modify, generate, and recall symbolic, non-linguistic information (Linn and Petersen, 1985; Tracy, 1987; Hegarty and Waller, 2005). Generally, three categories of spatial ability are distinguished in the literature, namely spatial perception, spatial visualization, and mental rotation (Linn and Petersen, 1985; Hegarty and Waller, 2005). Spatial perception involves determining spatial relationships with respect to the orientation of one's own body, in spite of distracting information. Spatial visualization is commonly associated with tasks that involve complicated, multistep manipulations of spatially presented information. Mental rotation includes the ability to mentally remember and subsequently rotate an object in the space (Linn and Petersen, 1985; Hegarty and Waller, 2005). Numerous studies have demonstrated that constructive play activities contribute to the development of spatial ability, in specific mental rotation (Tracy, 1987; Brosnan, 1998; Caldera et al., 1999; Wolfgang et al., 2001; Grimshaw et al., 2002; Bjorklund and Douglas-Brown, 2008; Levine etal., 2012). In the present study, spatial ability is, therefore, referred to as the performance on mental rotation tasks.

According to the scientific literature, constructive play activities like Legos, blocks, and jigsaw puzzles exert the most influence on spatial ability (Mitchell, 1973; Pomerleau et al., 1990; Caldera et al., 1999; Levine et al., 2012). For example, evidence shows that the more children play with Legos, the more they improve in their spatial skills (Brosnan, 1998; Wolfgang et al., 2003). Besides playing with Legos, also block play has shown a positive relation with children's spatial ability (Sprafkin et al., 1983; Tracy, 1987; Caldera et al., 1999). Preschool children that are more interested in block play and reproducing complex block models perform better on 
spatial ability tasks. Also jigsaw puzzles are examined in relation with spatial ability. Recent research of Levine et al. (2012) has revealed that the frequency of playing with jigsaw puzzles contributed to the development of spatial ability. Jigsaw puzzles appear to appeal to both the mental and physical rotation of the pieces to fit them into different places.

\section{THE RELATION BETWEEN SPATIAL ABILITY AND MATHEMATICAL WORD PROBLEM SOLVING}

Besides the positive relation between constructive play and children's spatial ability, a positive relation between spatial ability and mathematical ability, particularly mathematical word problem solving, is also reported in several studies (Guay and McDaniel, 1977; Lean and Clements, 1981; Tracy, 1987; Casey et al., 1992; Hegarty and Kozhevnikov, 1999; Kozhevnikov et al., 2002; BlattoVallee etal., 2007; Beentjes, 2008). Blatto-Vallee etal. (2007) showed, for example, that spatial ability explained almost 20\% of unique variance in mathematical word problem-solving performance. Casey et al. (1997, 2001, 2008) reported that the direct role of spatial ability in mathematical word problem solving lies in performing the actual mathematical operations and numerical reasoning. Other studies have shown the importance of spatial ability in the production of visual-schematic representations (e.g., Hegarty and Kozhevnikov, 1999; Van Garderen, 2006; Krawec, 2010). In order to facilitate the understanding of the text base of a mathematical word problem, one has to make a coherent visual representation of the essential information of the problem. These visual representations include the spatial relations between solution-relevant elements of the word problem text (e.g., Hegarty and Kozhevnikov, 1999; Van Garderen and Montague, 2003; Thevenot and Oakhill, 2006; Van Garderen, 2006; Thevenot, 2010). To be able to make these types of representations, spatial ability is needed. So, children with good spatial skills are better able to make visualschematic representations than children with poor spatial skills (e.g., Hegarty and Kozhevnikov, 1999; Van Garderen and Montague, 2003; Van Garderen, 2006; Krawec, 2010). The production of visual-schematic representations is found to be positively related to the performance on mathematical word problems (Van Garderen and Montague, 2003; Van Garderen, 2006; Krawec, 2010).

\section{THE PRESENT STUDY}

In summary, the scientific literature reports a positive relation between children's constructive play activities and spatial ability. Spatial ability increases as children engage more in playing with Legos, blocks, and jigsaw puzzles (Linn and Petersen, 1985; Tracy, 1987; Hegarty and Waller, 2005). Moreover, the positive relation between spatial ability and mathematical word problem-solving performance is also commonly investigated (Casey et al., 1997, 2001, 2008; Hegarty and Kozhevnikov, 1999). A relation between constructive play and mathematical word problem-solving performance is, however, not reported yet. A limited amount of studies have shown a positive relation between constructive play and more general math skills (Serbin and Connor, 1979; Caruso, 1993; Wolfgang et al., 2001). For example, the studies of Wolfgang et al. (2001) and Beentjes (2008) revealed that block play among preschoolers was a predictor of later school achievement in mathematics, when controlled for IQ and gender. All these studies did, however, not have a focus on mathematical word problem solving in particular. To our knowledge, this is one of the first studies that investigate the relation between constructive play and mathematical word problem-solving performance with spatial ability serving as a mediator. According to the statistical literature, a mediator explains the relation between the independent and the dependent variable. Rather than hypothesizing a direct causal relationship between the independent variable and the dependent variable, a mediational model hypothesizes that the independent variable causes the mediator variable, which in turn causes the dependent variable (for more information, see Shrout and Bolger, 2002; Preacher and Hayes, 2008; Hayes, 2009).

The mediating role of spatial ability in the relation between constructive play and mathematical word problem-solving performance is reflected in the hypothetical (mediation) model reported in Figure 1.

As studies have demonstrated that there is a difference in the extent in which boys and girls are engaged in constructive play activities (see e.g., Serbin and Connor, 1979; Tracy, 1987; Scholten, 2008), sex is added as a covariate to the mediation model.

\section{MATERIALS AND METHODS SAMPLE}

This study contained data from 128 Dutch sixth-grade children (64 boys, $M_{\text {age }}=11.73$ years, SD $_{\text {age }}=0.43$ years and 64 girls, $M_{\text {age }}=11.72$ years, $\mathrm{SD}_{\text {age }}=0.39$ years) from eight elementary schools in The Netherlands. Parents/caretakers provided written informed consent based on printed information about the purpose of the study.

\section{INSTRUMENTS AND MEASUREMENT PROCEDURE}

Children's mathematical word problem-solving performance and spatial ability were administered by three trained independent research assistants in a session of approximately $25 \mathrm{~min}$. Constructive play was examined with a questionnaire filled out by one of the parents/caretakers.

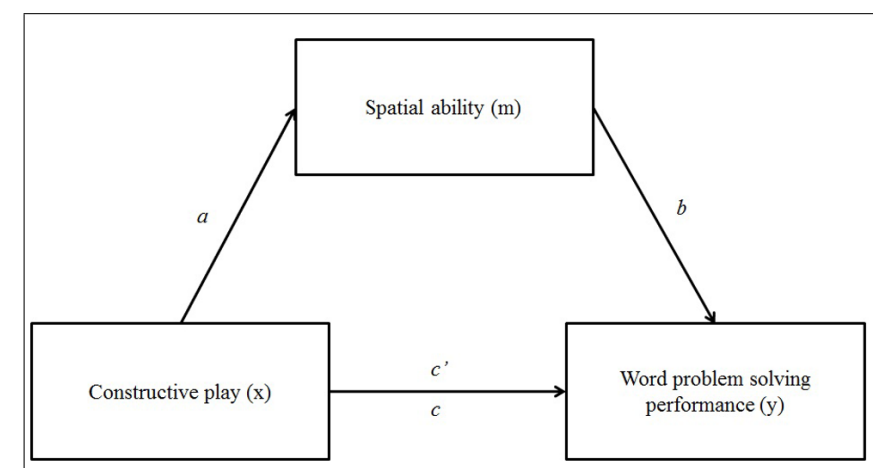

FIGURE 1 | Hypothesized mediation model including the independent variable (i.e., constructive play, $x$ ), mediator (i.e., spatial ability, $m$ ), and dependent variable (i.e., word problem solving performance, $y$ ). 


\section{Mathematical word problem-solving performance}

Mathematical word problem-solving performance was examined with the Mathematical Processing Instrument (MPI), which was first translated to Dutch. The MPI consisted of 14 mathematical word problems based on previous studies (Hegarty and Kozhevnikov, 1999; Van Garderen and Montague, 2003, see Appendix A). The internal consistency (Cronbach's $\alpha$ ) of this instrument, measured in American participants, is 0.78 (Hegarty and Kozhevnikov, 1999). The Cronbach's $\alpha$ of the MPI in this study was 0.72 . The word problems were printed on cards and presented in four different orders. All problems were read out loud to the children to control for differences in decoding skill. Furthermore, children were allowed to solve each word problem within a maximum of $3 \mathrm{~min}$ and during this time the experimenter did not speak to the child. To be sure those children had enough time to solve the mathematical word problems, a pilot study was conducted with five sixth-grade students. The results of the pilot study showed that every child was able to solve each of the 14 items of the MPI within the required $3 \mathrm{~min}$. The number of mathematical word problems solved correctly was used as the dependent variable in the analyses.

\section{Constructive play}

In order to determine to what extent children show constructive play behavior, a short questionnaire was forwarded to their parents/caretakers. They were asked to indicate on a 4-point Likert scale ( $1=$ never, $4=$ often) to what extent their child has undertaken the, for this study, representative constructive play activities (i.e., playing with Legos, blocks, and jigsaw puzzles). The internal consistency of this questionnaire was sufficient (Cronbach's $\alpha=0.71$ ). A sum score was created by adding the scores on the three, for this study representative, constructive play activities. The higher is the sum score, the more the student is involved in constructive play activities. The sum score was added as the independent variable in the analyses.

\section{Spatial ability}

The picture rotation task (Quaiser-Pohl, 2003) is a standardized task that was used to measure mental rotation. In the picture rotation task, children were asked to rotate a nonmanipulated picture of an animal at the left of a vertical line. The three pictures at the right of the vertical line showed the rotated and/or mirrored image of that same animal. One of these three pictures was only rotated; two of these pictures were both rotated and mirrored. Children had to decide which of the three pictures was only rotated. Children had $1.5 \mathrm{~min}$ to finish this task. The internal consistency of this measure in the present study was high (Cronbach's $\alpha=0.93$ ). Figure 2 shows one of the 30 test items of the picture rotation task. The accuracy on this task was used as the mediator in the analyses.

\section{DATA ANALYSIS}

The mediating effect of constructive play on word problem-solving performance via spatial ability was tested using bootstrap methods (Shrout and Bolger, 2002; Hayes, 2009). Bootstrap method has been validated in the literature and is preferred over other methods in assessing the existence of mediation among variables. Preference based on the fact that other methods for testing indirect effects assume a standard normal distribution when calculating the $p$-value for the indirect effect, whereas bootstrapping does not assume normality of the sampling distribution. In addition, bootstrap method repeatedly samples from the dataset, estimating the indirect effect with each resampled dataset. This process is repeated thousands of times, producing bias-corrected accelerated confidence intervals for the indirect effect (Preacher and Hayes, 2008).

\section{RESULTS \\ DESCRIPTIVE STATISTICS}

Table 1 presents the correlations between, and the means and standard deviations of, the four measures of this study. The table shows that the correlations among the constructive play, spatial ability and word problem-solving performance are moderate to strong. No significant correlation is found among sex and the three key measures of this study.

\section{INVESTIGATING THE MEDIATING ROLE OF SPATIAL ABILITY}

Mediation was tested by regressing the dependent variable (i.e., word problem-solving performance) on spatial ability in the presence of constructive play and sex. Analyses utilizing the

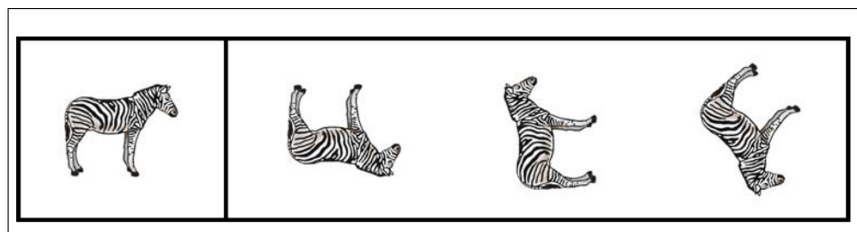

FIGURE 2 |The picture rotation task (based on Quaiser-Pohl, 2003).

Table 1 | Intercorrelations, means, standard deviations, and ranges of the measures of this study.

\begin{tabular}{|c|c|c|c|c|c|c|c|c|}
\hline 1. Constructive play & - & & & & 73 & 7.22 & 2.22 & 9.00 \\
\hline 3. Word problem-solving performance & $0.35^{* *}$ & $0.55^{* *}$ & - & & 128 & 6.68 & 2.87 & 14.00 \\
\hline 4. Sex & -0.16 & -0.14 & -0.16 & - & 128 & - & - & - \\
\hline
\end{tabular}

${ }^{*} p<0.05,{ }^{*} p<0.001$. 
Table 2 | Parameter estimates of the model examining the mediation role of spatial ability in the relation between constructive play and word problem-solving performance.

\begin{tabular}{|c|c|c|c|c|c|}
\hline Model & Estimate & SE & $p$ & $\mathrm{Cl}$ (lower) & $\mathrm{Cl}$ (upper) \\
\hline \multicolumn{6}{|c|}{ Model without mediator } \\
\hline $\mathrm{CP} \rightarrow \mathrm{WPS}(c)$ & 0.38 & 0.14 & $<0.01$ & 0.11 & 0.66 \\
\hline Sex $\rightarrow$ WPS & -1.44 & 0.60 & $<0.05$ & -2.63 & -0.24 \\
\hline$R^{2}(y, x)$ & 0.19 & - & - & - & - \\
\hline Intercept & 2.86 & 1.04 & $<.01$ & 0.78 & 4.94 \\
\hline \multicolumn{6}{|c|}{ Model 1: SP as dependent variable } \\
\hline $\mathrm{CP} \rightarrow \mathrm{SP}(a)$ & 0.75 & 0.41 & $<0.05$ & -0.06 & 1.56 \\
\hline Sex $\rightarrow$ SP & -3.33 & 1.79 & 0.07 & -6.90 & 0.25 \\
\hline Sex $\rightarrow$ WPS & -0.89 & 0.54 & 0.10 & -1.97 & 0.18 \\
\hline Indirect effects $(a \times b)$ & 0.12 & 0.08 & $<0.05$ & 0.128 & 0.27 \\
\hline$R^{2}(m, x)$ & 0.10 & - & - & - & - \\
\hline$R^{2}(y, m, x)$ & 0.38 & - & - & - & - \\
\hline
\end{tabular}

Regression weights $a, b, c$, and $c^{\prime}$ are illustrated in Figure 3. $R^{2}(y, x)$ is the proportion of variance in y explained by $x, R^{2}$ ( $\left.m, x\right)$ is the proportion of variance in $m$ explained by $x$ and $m$. the $95 \% \mathrm{Cl}$ for $a \times b$ is obtained by the bias-corrected bootstrap wit 5000 resamples. CP (constructive play) is the independent variable ( $x$ ), $\mathrm{SP}$ (spatial ability) is the mediator ( $\mathrm{m}$ ), and WPS (word problem-solving performance) is the outcome $(\mathrm{y}) . \mathrm{Cl}$ (lower $=$ lower bound of $95 \%$ confidence interval; $\mathrm{Cl}$ (upper) = upper bound.

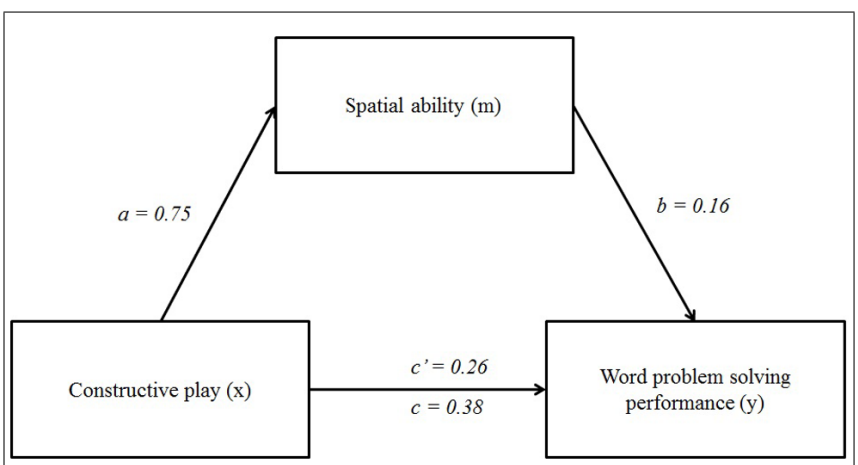

FIGURE 3 | Results of the mediation analysis ( $N=128)$. Sex was included in the equations as a statistical control but is not presented for reasons of clarity.

bootstrap method ( 5000 bootstrap samples were used) confirmed the existence of a mediation effect of constructive play on word problem-solving performance via spatial ability (see Table 2). However, the results showed that there is a partial, but not complete mediation, because the measured effect between constructive play and word problem-solving performance is not zero upon fixing the mediator variable (i.e., spatial ability, Preacher and Hayes, 2008). The value of the indirect effect of spatial ability can be calculated as follows:

$$
\begin{aligned}
& B_{\text {indirect }}=B_{(\mathrm{a})}{ }^{*} B_{(\mathrm{b})}=0.75 \times 0.16=0.12, \text { and } \\
& B_{\text {indirect }} / B_{\text {total }}=0.12 / 0.38=0.3158
\end{aligned}
$$

Thus, spatial ability explained $31.58 \%$ of the relation between constructive play and students' mathematical word problemsolving performance. The absence of a zero in the confidence interval for the indirect pathways indicated that the indirect effect was significantly different from zero at $p<0.05$, two-tailed.

The complete model (including constructive play, spatial ability, and sex) explained $38.16 \%$ of the variance in students word problem-solving performance $\left(R^{2}=0.38\right)$, which is a large effect (Green and Salkind, 2008; Fairchild et al., 2009).

\section{DISCUSSION}

The purpose of the present study was to investigate if spatial ability acts as a mediator in the relation between constructive play and mathematical word problem-solving performance in sixth-grade elementary school children. To our knowledge, this is one of the first studies that examined the mediating role of spatial ability in this particular relation. In previous studies, relations between constructive play and spatial ability (e.g., Brosnan, 1998; Bjorklund and Douglas-Brown, 2008), and between spatial ability and mathematical word problem-solving performance (e.g., Hegarty and Kozhevnikov, 1999; Van Garderen and Montague, 2003; BlattoVallee et al., 2007) are reported. The relation between constructive play and mathematical word problem-solving performance has, however, not been established yet. 
The results of this study showed that spatial ability acted as a partial mediator in the relation between constructive play and children's mathematical word problem-solving performance. This implies that children who were frequently engaged in constructive play in their past have better spatial skills and, as a result, show a higher performance on mathematical word problems. The variables in this study (i.e., constructive play, spatial ability, and sex) explained $38.16 \%$ of the variance in performance on solving mathematical word problems. Furthermore, 31.58\% of the relation between constructive play and mathematical word problem-solving performance is explained by spatial ability.

Note that the findings of this study support the assessment of a mediating effect based on current recommendations using bootstrap approaches (Shrout and Bolger, 2002; Hayes, 2009) ${ }^{1}$.

\section{LIMITATIONS}

Three limitations of the study should be mentioned. The first limitation of this study included the fact that only one task was used in the analyses to measure spatial ability (i.e., mental rotation). Ideally, method triangulation should be applied. The use of more tasks allows a more reliable measurement of the construct "spatial ability" and reduces the chance of possible measurement errors (Woolderink, 2009). The second limitation pertains to the correlational nature of the data, which made it impossible to draw conclusions about any causal relationships among constructive play, spatial ability, and mathematical word problem-solving performance. The results of this study only showed that these variables were associated with each other. Future experimental studies in which the variables will be manipulated should make it possible to draw stronger conclusions concerning causal relationships between the aspects which are important in mathematical word problem solving. The last limitation covers the way in which the constructive play activities of the children were administered. In the present study, a third party (i.e., the parents), filled out the questionnaires regarding the extent to which children show constructive play behavior. Although parents were able to provide a reliable image of the constructive play activities in which their children are/were involved, in future studies it would be even more reliable to directly observe these play activities.

\section{IMPLICATIONS AND DIRECTIONS FOR FUTURE RESEARCH}

The present study contributed to the increasing amount of scientific literature regarding the processes that are involved in learning mathematics, particularly mathematical word problem solving. An interesting focus of future research is to investigate the existence of individual differences in the specific relations between the three key variables of this study (i.e., constructive play, spatial ability, and mathematical word problem-solving performance). Although not supported by the results of the present study, several authors have demonstrated that boys and girls differ in the extent in which they engage in constructive play (Serbin and Connor, 1979; Tracy, 1987; Scholten, 2008). That is, boys tend to play more with socalled masculine or constructive toys, like Legos and blocks, than

\footnotetext{
${ }^{1}$ This assessment of mediation is also support by the statistical approach that Baron and Kenny (1986) used in their research.
}

girls (Serbin and Connor, 1979; Tracy, 1987). Because the scientific literature gives no clear indications that sex differences exist in spatial ability (e.g., McGee, 1979; Voyer et al., 1995), examining the mediating role of spatial ability for both boys and girls separately might be an interesting topic for follow-up studies.

The results of this study also have a strong practical relevance. Parents/caretakers should be aware of the importance of constructive play activities in childhood. According to the findings of this study, activities like playing with Legos, blocks, and jigsaw puzzles, are positively related to students' spatial skills, which, in turn, is positively related to their performance on mathematical word problems. Parents/caretakers should, therefore, create opportunities to play with constructive toys. Also elementary school teachers should provide constructive learning material to their children and stimulate to use it by giving them appropriate instruction. Finally, this research accentuated the importance of spatial ability in mathematical word problem-solving performance. In line with previous research (e.g., Hegarty and Kozhevnikov, 1999; Van Garderen, 2006), spatial ability was found to play a key role in solving mathematical word problems, especially in the production of visual-schematic representations. The training of spatial skills and the development of visual-schematic representations should, therefore, have a prominent role in word problem-solving instruction of primary school mathematics education.

\section{REFERENCES}

Baron, R. M., and Kenny, D. A. (1986). The moderator-mediator variable distinction in socialpsychological research: conceptual, strategic, and statistical considerations. J. Personal. Soc. Psychol. 51, 1173-1182. doi: 10.1037/0022-3514.51. 6.1173

Beentjes, I. (2008). Ruimtelijke Exploratie en de Ontwikkeling van Number Sense [Spatial Exploration in the Development of Number Sense]. Master thesis, Orthopedagogiek, Utrecht University, Utrecht.

Bjorklund, D. F., and Douglas-Brown, D. (2008). Physical play and cognitive development: integrating activity, cognition and education. Child Dev. 69, 604-606. doi: 10.1111/j.1467-8624.1998.tb06229.x

Blatto-Vallee, G., Kelly, R. R., Gaustad, M. G., Porter, J., and Fonzi, J. (2007). Visualspatial representation in mathematical problem solving by deaf and hearing students. J. Deaf Stud. Deaf Educ. 12, 432-448. doi: 10.1093/deafed/enm022

Brosnan, M. J. (1998). Spatial ability in children's play with Lego blocks. Percept. Mot. Skills 87, 19-28. doi: 10.2466/pms.1998.87.1.19

Caldera, Y. M., Culp, A. M., O’Brian, M., Truglio, R. T., Alvarez, M., and Huston, A. (1999). Children's play preferences, construction play with blocks and visual spatial skills: are they related? Int. J. Behav. Dev. 23, 855-872. doi: 10.1080/016502599383577

Caruso, D. A. (1993). Dimensions of quality in infants' exploratory behavior: relationships toproblem solving ability. Infant Behav. Dev. 16, 441-454. doi: 10.1016/0163-6383(93)80003-Q

Casey, M. B., Andrews, N., Schindler, H., Kersh, J. E., Samper, A., and Copley, J. (2008). The development of spatial skills through interventions involving block building activities. Cogn. Instr. 26, 269-309. doi: 10.1080/073700008021 77177

Casey, M. B., Nuttall, R. L., and Pezaris, E. (1997). Mediators of gender differences in mathematics college entrance test scores: a comparison of spatial skills with internalized beliefs and anxieties. Dev. Psychol. 33, 669-680. doi: 10.1037/00121649.33.4.669

Casey, M. B., Nuttall, R. L., and Pezaris, E. (2001). Spatial-mechanical reasoning skills versus mathematics self-confidence as mediators of gender differences on mathematics subtests using cross-national gender-based items. J. Res. Math. Educ. 32, 28-57. doi: 10.2307/749620

Casey, M. B., Pezaris, E., and Nuttall, R. L. (1992). Spatial ability as a predictor of math achievement: the importance of sex and handedness patterns. Neuropsychologia 30, 35-45. doi: 10.1016/0028-3932(92)90012-B 
Fairchild, A. J., Mackinnon, D. P., Taborga, M. P., and Taylor, A. B. (2009). R2 effect-size measures for mediation analysis. Behav. Res. Methods 41, 486-498. doi: 10.3758/BRM.41.2.486

Green, S. B., and Salkind, N. J. (2008). Using SPSS for Windows and Macintosh. Analyzing and Understanding Data, 5th edn. London: Pearson Education.

Grimshaw, G. M., Sitarenios, G., and Finegan, J. A. K. (2002). Mental rotation at 7 years - relations with prenatal testosterone levels and spatial play experiences. Brain Cogn. 29, 85-100. doi: 10.1006/brcg.1995.1269

Guay, R. B., and McDaniel, E. D. (1977). The relationship between mathematics achievement and spatial abilities among elementary school children. J. Res. Math. Educ. 8, 211-215. doi: 10.2307/748522

Hayes, A. F. (2009). Beyond Baron and Kenny: statistical mediation analysis in new millennium. Commun. Monogr. 76, 408-420. doi: 10.1080/03637750903310360

Hegarty, M., and Kozhevnikov, M. (1999). Types of visual-spatial representations and mathematical problem solving. J. Educ. Psychol. 91, 684-689. doi: 10.1037/0022-0663.91.4.684

Hegarty, M., and Waller, D. A. (2005). "Individual differences in spatial abilities," in The Cambridge Handbook of Visuospatial Thinking, eds P. Shah and A. Miyake (Cambridge: Cambridge University Press), 121-169. doi: 10.1017/CBO9780511610448.005

Kozhevnikov, M., Hegarty, M., and Mayer, R. E. (2002). Revising the visualizerverbalizer dimension: evidence for two types of visualizers. Cogn. Instr. 20, 47-77. doi: 10.1207/S1532690XCI2001_3

Krawec, J. L. (2010). Problem representation and mathematical problem solving of students with varying abilities, Doctoral dissertation, University of Miami, Miami.

Lean, G., and Clements, M. A. K. (1981). Spatial ability, visual imagery, and mathematical performance. Educ. Stud. Math. 12, 267-299. doi: 10.1007/BF00311060

Levine, S. C., Ratliff, K. R., Huttenlocher, J., and Cannon, J. (2012). Early puzzle play: a predictor of preschoolers' spatial transformation skill. Dev. Psychol. 48, 530-542. doi: 10.1037/a0025913

Linn, M. C., and Petersen, A. C. (1985). Emergence and characterization of gender differences in spatial abilities: a meta-analysis. Child Dev. 56, 1479-1498. doi: $10.2307 / 1130467$

McGee, M. G. (1979). Human spatial abilities: psychometric studies and environmental, genetic, hormonal, and neurological influences. Psychol. Bull. 86 889-918. doi: 10.1037/0033-2909.86.5.889

Mitchell, E. (1973). The learning of sex roles through toys and books: a woman's view. Young Child. 28, 226-231.

Pomerleau, A., Malcuit, G., and Seguin, R. (1990). 5-month-old girls' and boys' exploratory behaviors in the present of familiar and unfamiliar toys. J. Genet. Psychol. 153, 47-61. doi: 10.1080/00221325.1992.10753701

Preacher, K. J., and Hayes, A. F. (2008). Asymptotic and resampling strategies for assessing and comparing indirect effects in multiple mediator models. Behav. Res. Methods 40, 879-891. doi: 10.3758/BRM.40.3.879

Quaiser-Pohl, C. (2003). The mental cutting test 'Schnitte" and the picture rotation test - two new measures to assess spatial ability. Int. J. Test. 3, 219-231. doi: 10.1207/S15327574IJT0303_2

Scholten, F. (2008). Geslachtsverschillen in spelgedrag tussen jongens en meisjes [Sex Differences in Play Behavior], Bachelor thesis, Kinder-en Jeugdpsychologie, University of Tilburg, Tilburg.

Serbin, L. A., and Connor, J. M. (1979). Sex typing of children: play preference and patterns of cognitive performance. J. Genet. Psychol. 134, 315-316. doi: 10.1080/00221325.1979.10534065
Shrout, P. E., and Bolger, N. (2002). Mediation in experimental and nonexperimental studies: new procedures and recommendations. Psychol. Methods 7, 422-445. doi: 10.1037/1082-989X.7.4.422

Sprafkin, C., Serbin, L. A., Denier, C., and Connor, J. M. (1983). "Sex-differentiated play: cognitive consequences and early interventions," in Social and Cognitive Skills: Sex Roles and Child's Play, ed. M. B. Liss (New York: Academic Press).

Thevenot, C. (2010). Arithmetic word problem solving: evidence for the construction of a mental model. Acta Psychol. 133, 90-95. doi: 10.1016/j.actpsy.2009.10.004

Thevenot, C., and Oakhill, J. (2006). Representations and strategies for solving dynamic and static arithmetic word problems: the role of working memory capacities. Eur. J. Cogn. Psychol. 18, 756-775. doi: 10.1080/09541440500 412270

Tracy, D. M. (1987). Toys, spatial ability and science and mathematics achievement: are they related? Sex Roles 17, 115-138. doi: 10.1007/BF00287620

Van Garderen, M. (2006). Spatial visualization, visual imagery, and mathematical problem solving of students with varying abilities. J. Learn. Disabil. 39, 496-506. doi: 10.1177/00222194060390060201

Van Garderen, M., and Montague, M. (2003). Visual-spatial representation, mathematical problem solving, and students of varying abilities. Learn. Disabil. Res. Pract. 18, 246-254. doi: 10.1111/1540-5826. 00079

Voyer, D., Voyer, S., and Bryden, M. P. (1995). Magnitude of sex differences in spatial abilities: a meta-analysis and consideration of critical variables. Psychol. Bull. 117, 25-270. doi: 10.1037/0033-2909.117.2.250

Wolfgang, C. H., Stannard, L. L., and Jones, I. (2001). Block play performance among preschoolers as a predictor of later school achievement in mathematics. J. Res. Child. Educ. 15, 173-180. doi: 10.1080/025685401095 94958

Wolfgang, C. H., Stannard, L. L., and Jones, I. (2003). Advanced constructional play with LE-GOs among preschoolers as a predictor of later school achievement in mathematics. Early Child Dev. Care 173, 467-475. doi: 10.1080/0300443032000088212

Woolderink, S. (2009). Zicht op Ouderschap [Perspectives on Parenthood], Master thesis, Orthopedagogiek, VU University Amsterdam, Amsterdam.

Conflict of Interest Statement: The authors declare that the research was conducted in the absence of any commercial or financial relationships that could be construed as a potential conflict of interest.

Received: 14 April 2014; accepted: 02 July 2014; published online: 17 July 2014.

Citation: Oostermeijer M, Boonen AJH and Jolles J (2014) The relation between children's constructive play activities, spatial ability and mathematical word problemsolving performance: a mediation analysis in sixth-grade students. Front. Psychol. 5:782. doi: $10.3389 /$ fpsyg.2014.00782

This article was submitted to Educational Psychology, a section of the journal Frontiers in Psychology.

Copyright (C) 2014 Oostermeijer, Boonen and Jolles. This is an open-access article distributed under the terms of the Creative Commons Attribution License (CC BY). The use, distribution or reproduction in other forums is permitted, provided the original author(s) or licensor are credited and that the original publication in this journal is cited, in accordance with accepted academic practice. No use, distribution or reproduction is permitted which does not comply with these terms. 


\section{APPENDIX A}

The mathematical word problems on the MPI (Hegarty and Kozhevnikov, 1999):

1. At each of the two ends of a straight path, a man planted a tree and then every $5 \mathrm{~m}$ along the path he planted another tree. The length of the path is $15 \mathrm{~m}$. How many trees were planted?

2. On one side of a scale, there is a $1 \mathrm{~kg}$ weight and half a brick. On the other side, there is one full brick. The scale is balanced. What is the weight of the brick?

3. A balloon first rose $200 \mathrm{~m}$ from the ground, then moved $100 \mathrm{~m}$ to the east, then dropped $100 \mathrm{~m}$. It then traveled $50 \mathrm{~m}$ to the east, and finally dropped straight to the ground. How far was the balloon from its original starting point?

4. In an athletics race, Jim is $4 \mathrm{~m}$ ahead of Tom and Peter is $3 \mathrm{~m}$ behind Jim. How far is Peter ahead of Tom?

5. A square (A) has an area of $1 \mathrm{~m}^{2}$. Another square (B) has sides twice as long. What is the area of square $\mathrm{B}$ ?

6. From a long stick of wood, a man cut 6 short sticks, each 2 feet long. He then found he had a piece of 1 foot long left over. Find the length of the original stick.

7. The area of a rectangular field is $60 \mathrm{~m}^{2}$. If its length is $10 \mathrm{~m}$, how far would you have traveled if you walked the whole way around the field?
8. Jack, Paul, and Brian all have birthdays on 1 January, but Jack is 1 year older than Paul and Jack is 3 years younger than Brian. If Brian is 10 years old, how old is Paul?

9. The diameter of a tin of peaches is $10 \mathrm{~cm}$. How many tins will fit in a box $30 \mathrm{~cm} \times 40 \mathrm{~cm}$ (one layer only)?

10. Four young trees were set out in a row $10 \mathrm{~m}$ apart. A well was situated beside the last tree. A bucket of water is needed to water two trees. How far would a gardener have to walk altogether if he had to water the four trees using only one bucket?

11. A hitchhiker set out on a journey of 60 miles. He walked the first 5 miles and then got a lift from a lorry driver. When the driver dropped him, he still had half of his journey to travel. How far had he traveled in the lorry?

12. How many picture frames $6 \mathrm{~cm}$ long and $4 \mathrm{~cm}$ wide can be made from a piece of framing $200 \mathrm{~cm}$ long?

13. On one side of a scale, there are three pots of jam and a $100 \mathrm{~g}$ weight. On the other side, there are a $200 \mathrm{~g}$ and a $500 \mathrm{~g}$ weight. The scale is balanced. What is the weight of a pot of jam?

14. A ship was sailing North-West. It made a turn of $90^{\circ}$ to the right. An hour later it made a turn of $45^{\circ}$ to the left. In what direction was it then traveling? 